\title{
Evaluation of sulphasalazine in the treatment of spondyloarthropathies
}

\author{
Maxime Dougados, Andreas Maetzel, Mustapha Mijiyawa, Bernard Amor
}

\begin{abstract}
Sulphasalazine has been shown to have an effect in patients with spondyloarthropathies, but the clinical indication for its use is controversial and its long term effect has not yet been evaluated. Treatment with sulphasalazine was analysed retrospectively in a group of 372 patients with a wide range of spondyloarthropathies to determine subsets of patients showing differential effects of the drug. One hundred and one patients received sulphasalazine at a mean daily dose of $2 \mathrm{~g}$ (ankylosing spondylitis, 54 patients; psoriatic arthritis, 21 patients; reactive arthritis, four patients; arthritis related to inflammatory bowel disease, six patients; undifferentiated spondyloarthropathy, 16 patients). A comparison between treated and untreated patients suggests that only patients with active and severe disease were treated whatever the precise diagnosis or the amount of axial disease in the spondyloarthropathy.

After six months of treatment improvement was noted in 59 patients unrelated to their subgroup or amount of axial disease. After a mean follow up of 20 months, 37 patients were still receiving treatment, 33 had discontinued the drug because of inefficacy, 14 because of side effects, six because of remission of the disease, and 11 for other reasons. Comparison between the beginning and end of treatment showed a statistically significant decrease in morning stiffness, erythrocyte sedimentation rate, and daily dose of non-steroidal antiinflammatory drugs (NSAIDs).
\end{abstract}

It is concluded that: $(a)$ a low percentage of patients with spondyloarthropathy have active disease requiring treatment with sulphasalazine despite the use of NSAIDs $(27 \%$ in this study); (b) in this subgroup of patients sulphasalazine seems to be of clinically relevant benefit in 59\%; and (c) this benefit does not seem to be correlated with either the precise diagnosis of spondyloarthropathy or the amount of axial disease.

(Ann Rheum Dis 1992; 51: 955-958)

The spondyloarthropathies consist of several diseases, including reactive arthritis, psoriatic arthritis, arthritis associated with inflammatory bowel disease, a subgroup of juvenile chronic arthritis, and ankylosing spondylitis, the latter being the prototype of this group of interrelated disorders. ${ }^{12}$ Classification criteria for the whole range of spondyloarthropathies have been proposed to encompass not only patients with these well defined diseases but also patients with undifferentiated spondyloarthropathy. ${ }^{3} 4$ Within the group of spondyloarthropathies patient classification may be based on either the precise diagnosis-for example, ankylosing spondylitis, psoriatic arthritis-or the clinical presentation of the disease (axial disease, articular peripheral disease, enthesiopathic lesions, extra-articular symptoms). The monitoring and treatment of these diseases are related more to their clinical presentation than to their precise diagnosis. ${ }^{5}$

Sulphasalazine was developed and manufactured to cure rheumatoid arthritis by eliminating the putative cause, a group B streptococcal intestinal infection. After a temporary demise sulphasalazine gained a position as a second line disease modifying drug mainly through the work of McConkey et al: ${ }^{6}$ Sulphasalazine has been acccepted as the drug of choice in the treatment of inflammatory bowel disease. ${ }^{7}$ Although the stimulus for using sulphasalazine in the treatment of spondyloarthropathy did not derive directly from its use in patients with rheumatoid arthritis, there are several arguments for considering it: $(a)$ the common association between inflammatory bowel disease and spondyloarthropathy ${ }^{2} ;(b)$ the description of inflammatory lesions in the ileum of patients with spondyloarthropathy; ${ }^{89}$ and (c) the reported association between disturbances in bowel flora and ankylosing spondylitis. ${ }^{10}$ Much of the rationale postdated the early clinical studies." workers have shown that sulphasalazine may be effective in the treatment of spondyloarthropathies. Meta-analysis carried out on five randomised controlled trials ${ }^{12-16}$ suggests that sulphasalazine is a safe and effective drug in the short term (three to six months) treatment of ankylosing spondylitis. ${ }^{17}$ Other studies suggest that a beneficial effect of sulphasalazine might be observed not only in ankylosing spondylitis but also in the articular symptoms of reactive arthritis ${ }^{18}$ and psoriatic arthritis, ${ }^{19} 20$ and on the extra-articular symptoms of spondyloarthropathies such as psoriasis ${ }^{21}$ and uveitis. ${ }^{22}$

All these clinical trials were short term (three to six months) and were conducted in selected patients. Therefore to identify a subgroup of patients with spondyloarthropathy who might preferentially respond to sulphasalazine we retrospectively analysed the patients monitored in our department by comparing those who did and did not receive sulphasalazine and those who did and did not respond to treatment. In the group of patients who received sulphasalazine the long term effect of the drug was evaluated by using life table analysis to calculate 
the percentage of patients receiving treatment after some time.

\section{Patients and methods}

The files of all inpatients or outpatients consulting two of the authors (BA and MD) in the department of rheumatology of Cochin Hospital in the period 1982-91 with a diagnosis of spondyloarthropathy were examined. All the patients who met the criteria for spondyloarthropathy ${ }^{34}$ were selected for study.

The basic disease related information was derived from the inpatient and outpatient files and consisted of the following: age, sex, HLAB27 positivity, subgroup of spondyloarthropathy (ankylosing spondylitis, psoriatic arthritis, reactive arthritis, arthritis related to inflammatory bowel disease, undifferentiated spondyloarthropathy), the rheumatological manifestations of spondyloarthropathy (axial disease, peripheral disease, enthesiopathy), the extra-articular features (uveitis, psoriasis, inflammatory bowel disease), severity of the spondyloarthropathy (hip disease, erosive arthritis), and treatment given.

For the patients who had received sulphasalazine the following parameters were noted: time of start of treatment relative to the onset of disease, duration of treatment, efficacy variables at entry and at the last visit (including night wakings due to pain, presence of morning stiffness, erythrocyte sedimentation rate $(\mathrm{mm}$

Table 1 Characteristics of the 372 patients with spondyloarthropathies who did and did not receive sulphasalazine

\begin{tabular}{|c|c|c|c|}
\hline \multirow[t]{2}{*}{ Patient characteristics } & \multicolumn{2}{|c|}{ Sulphasalazine treatment ${ }^{*}$} & \multirow[t]{2}{*}{ p Valuet } \\
\hline & Yes $(n=101)$ & No $(n=271)$ & \\
\hline $\begin{array}{l}\text { Mean (SD) age (years) } \\
\text { Sex (F/M) } \\
\text { HLA-B27 positive/negative }\end{array}$ & $\begin{array}{l}35(15) \\
35 / 66 \\
69 / 28\end{array}$ & $\begin{array}{l}36(13) \\
91 / 180 \\
160 / 66\end{array}$ & $\begin{array}{l}\text { NS } \\
\text { NS } \\
\text { NS }\end{array}$ \\
\hline \multicolumn{4}{|l|}{ Subgroup of spondyloarthropathy } \\
\hline $\begin{array}{l}\text { Ankylosing spondylitis } \\
\text { Psoriatic arthritis }\end{array}$ & $\begin{array}{l}54 \\
21\end{array}$ & $\begin{array}{r}155 \\
62\end{array}$ & \\
\hline Reactive arthritis & 4 & 16 & NS \\
\hline Inflammatory bowel disease related arthritis & 6 & 7 & \\
\hline Undifferentiated spondyloarthropathy & 16 & 31 & \\
\hline \multicolumn{4}{|l|}{ Rheumatological manifestations } \\
\hline Axial disease (yes/no) & $83 / 18$ & $216 / 55$ & NS \\
\hline Peripheral disease (yes/no) & $78 / 23$ & $160 / 111$ & NS \\
\hline Enthesiopathy (yes/no) & $75 / 26$ & $158 / 113$ & $<0.01$ \\
\hline \multicolumn{4}{|l|}{ Severity of spondyloarthropathy } \\
\hline $\begin{array}{l}\text { Hip disease (yes/no) } \\
\text { Erosive arthritis (yes/no) }\end{array}$ & $16 / 84$ & $20 / 249$ & 0.01 \\
\hline \multicolumn{4}{|l|}{ Extra-articular features } \\
\hline Uveitis (yes/no) & 19/82 & $31 / 240$ & NS \\
\hline Psoriasis (yes/no) & $30 / 71$ & $74 / 196$ & NS \\
\hline
\end{tabular}

*Values given are either the number of patients with the variable or the mean (SD).

†Statistical significance determined by the $\chi^{2}$ test for the qualitative variables and the nonparametric Wilcoxon test for the continuous variables. NS=not significant.

Table 2 Efficacy variables in patients with spondyloarthropathy at the start of treatment with sulphasalazine and at the last visit while receiving treatment

\begin{tabular}{|c|c|c|c|}
\hline Variables* & $\begin{array}{l}\text { Start of treatment } \\
\text { with sulphasalazine }\end{array}$ & $\begin{array}{l}\text { Last visit while } \\
\text { receiving treatment }\end{array}$ & $p$ Valuet \\
\hline $\begin{array}{l}\text { Nocturnal awakenings due to pain }(n=53 \\
\text { Morning stiffness }(n=52) \\
\text { Mean (SD) erythrocyte sedimentation } \\
\text { (mm/first hour) (n=51) } \\
\text { Mean (SD) NSAIDs (daily } \\
\text { scoring) }(n=74) \ddagger\end{array}$ & $\begin{array}{l}33 \\
44 \\
\text { rate } \\
39(30) \\
11(7)\end{array}$ & $\begin{array}{l}16 \\
31 \\
28(20) \\
9(8)\end{array}$ & $\begin{array}{l}<0.01 \\
<0.01 \\
<0.01 \\
<0.01\end{array}$ \\
\hline
\end{tabular}

in first hour), platelet count, and the daily dose of non-steroidal anti-inflammatory drugs (NSAIDs) necessary for patient comfort according to a scoring reported previously: ${ }^{12}$ a score of 10 is given to a daily intake of $100 \mathrm{mg}$ indomethacin). A patient was considered as responding to treatment with sulphasalazine if after the first six months of treatment the decision to continue treatment for a longer period was taken. The reason for stopping treatment was noted as inefficacy, toxicity, remission of the disease, event unrelated to treatment or unknown reason.

Statistical analysis was carried out to compare the characteristics of the patients who did or did not receive sulphasalazine. In the group of patients who had received sulphasalazine changes in the efficacy variables during treatment were analysed using the $\chi^{2}$ test for the qualitative variables and by the non-parametric Wilcoxon rank sum test for intragroup comparison of the quantitative variables. The threshold of significance adopted was $5 \%$ (two tailed). The treatment termination curves were evaluated by the Kaplan-Meier method.

\section{Results}

PATIENTS AND STUDY COURSE

Between June 1982 and May 1991372 patients attending this department fulfilled the criteria for diagnosis of spondyloarthropathy. Sulphasalazine was given to 101 patients $(27 \%)$ at a mean (SD) daily dose of $2 \cdot 2(0 \cdot 6) \mathrm{g}$.

At the time of the study 37 patients were still receiving treatment; the other 64 patients had discontinued treatment with sulphasalazine for the following reasons: inefficacy, 33 patients; side effects, 14 patients; remission, six patients; other reasons, 11 patients.

\section{CHARACTERISTIC OF SPONDYLOARTHROPATHY WITH RESPECT TO TREATMENT WITH SULPHASALAZINE}

Table 1 summarises the main characteristics of the patients with respect to treatment with sulphasalazine. The patients who received sulphasalazine had more severe disease as hip disease and erosive arthritis were more commonly observed than in patients who did not receive sulphasalazine $(16 \% v 7 \%, p=0.01$ and $21 \% v 9 \%, \mathrm{p}<0.01$ respectively).

\section{TREATMENT WITH SULPHASALAZINE}

Table 2 summarises the changes in the efficacy variables between the start of treatment and the last visit while receiving treatment. Most of the patients had active disease when sulphasalazine treatment was initiated despite treatment with an optimum dose of NSAIDs. After treatment all these variables improved allowing a reduction in the daily intake of NSAIDs.

After the first six months of treatment, treatment was considered efficient in 59 of 101 patients. Table 3 summarises the characteristics of the patients who did and who did not respond to treatment. In these analyses a responder was defined as a patient who continued 
Table 3 Characteristics of the patients with spondyloarthropathy who did and did not respond to treatment with sulphasalazine

\begin{tabular}{|c|c|c|c|}
\hline \multirow[t]{2}{*}{ Variables } & \multicolumn{2}{|c|}{ Responder to sulphasalazine $e^{*}$} & \multirow[t]{2}{*}{ p Valuet } \\
\hline & Yes $(n=59)$ & No $(n=19)$ & \\
\hline $\begin{array}{l}\text { Age (years) } \\
\text { Sex (M/F) } \\
\text { HLA-B27 positive/negative } \\
\text { Subgroup of spondyloarthropathy }\end{array}$ & $\begin{array}{l}40(13) \\
35 / 24 \\
39 / 17\end{array}$ & $\begin{array}{l}37(13) \\
16 / 3 \\
13 / 6\end{array}$ & $\begin{array}{l}\text { NS } \\
0 \cdot 047 \\
\text { NS }\end{array}$ \\
\hline Ankylosing spondylitis & 33 & 11 & \\
\hline Psoriatic arthritis & 12 & 3 & \\
\hline Reactive arthritis & 12 & 1 & NS \\
\hline Inflammatory bowel disease related arthritis & 5 & 0 & \\
\hline Undifferentiated spondyloarthropathy & 8 & 4 & \\
\hline \multicolumn{4}{|l|}{ Rheumatological manifestations } \\
\hline Axial disease & 13 & 8 & \\
\hline Peripheral disease & 10 & 2 & NS \\
\hline Enthesiopathy & 36 & 9 & \\
\hline \multicolumn{4}{|l|}{ Severity of spondyloarthropathy } \\
\hline Hip disease (yes/no) & $9 / 50$ & $3 / 16$ & NS \\
\hline Erosive arthritis (yes/no) & $15 / 43$ & $0 / 19$ & $0 \cdot 036$ \\
\hline \multicolumn{4}{|l|}{ Extra-articular disease } \\
\hline $\begin{array}{l}\text { Uveitis (yes/no) } \\
\text { Psoriasis (yes/no) }\end{array}$ & $\begin{array}{l}13 / 46 \\
20 / 39\end{array}$ & $\begin{array}{l}4 / 15 \\
4 / 15\end{array}$ & $\begin{array}{l}\text { NS } \\
\text { NS }\end{array}$ \\
\hline
\end{tabular}

${ }^{*}$ A responder was defined as a patient who continued treatment over a six month period, a nonresponder as a patient who discontinued treatment because of inefficacy between the fourth and sixth month of treatment.

tStatistical significance was determined by the Wilcoxon test for the continuous variables and the $\chi^{2}$ test for the dichotomus variables. NS= not significant.

Table 4 Adverse reactions observed in 101 patients with spondyloarthropathy treated with sulphasalazine

\begin{tabular}{llll}
\hline Characteristics & $\begin{array}{l}\text { No of } \\
\text { patients }\end{array}$ & $\begin{array}{l}\text { No of } \\
\text { withdrawals* }\end{array}$ & $\begin{array}{l}\text { Time of } \\
\text { withdrawal (weeks) }\end{array}$ \\
\hline $\begin{array}{l}\text { Gastrointestinal disorders } \\
\text { Central nervous system disorders } \\
\quad \text { Insomnia }\end{array}$ & 15 & 8 & $1,4,4,26,30,30,39,100$ \\
$\begin{array}{c}\text { Dizziness } \\
\text { Skin reactions } \\
\text { Rash }\end{array}$ & 1 & 1 & 1 \\
$\begin{array}{c}\text { Haematological reactions } \\
\text { Anaemia } \\
\text { Leucopenia }\end{array}$ & 1 & 2 & 4,30 \\
Fever & 2 & 1 & 1 \\
\hline
\end{tabular}

* Fourteen patients withdrew from the study because of side effects. Two adverse reactions occurred in the same patient in two instances. treatment over a six month period (59 patients) and a non-responder was defined as a patient who discontinued treatment because of inefficacy between the fourth and sixth month (19 patients). On the basis of these definitions we could not show a relation between the efficacy of sulphasalazine and either the subgroup of spondyloarthropathy or the clinical presentation of spondyloarthropathy.

Table 4 shows that adverse reactions occurred in 23 patients and resulted in 14 withdrawals. The side effects observed are those usually reported with such treatment. Most of these side effects occurred within the first few weeks (eight patients withdrew from the study because of side effects within the first month of treatment). Such side effects also occurred after a longer period of treatment, however, resulting in eight late withdrawals.

Standard methods of life table analysis were applied to the 101 patients who received sulphasalazine. The end of treatment was taken as the endpoint. Once generated the total termination incidence curve was partitioned according to the main reason for treatment termination: inefficacy or adverse effects. The figure shows the incidence of treatment termination for all reasons, the termination incidence curve for treatment failure, and treatment termination due to adverse effects. By one year $46 \%$ of patients receiving sulphasalazine had stopped treatment and by two years $59 \%$ of patients had stopped.

\section{Discussion}

In this study patients with spondyloarthropathy were treated with sulphasalazine only if their disease was active despite treatment with

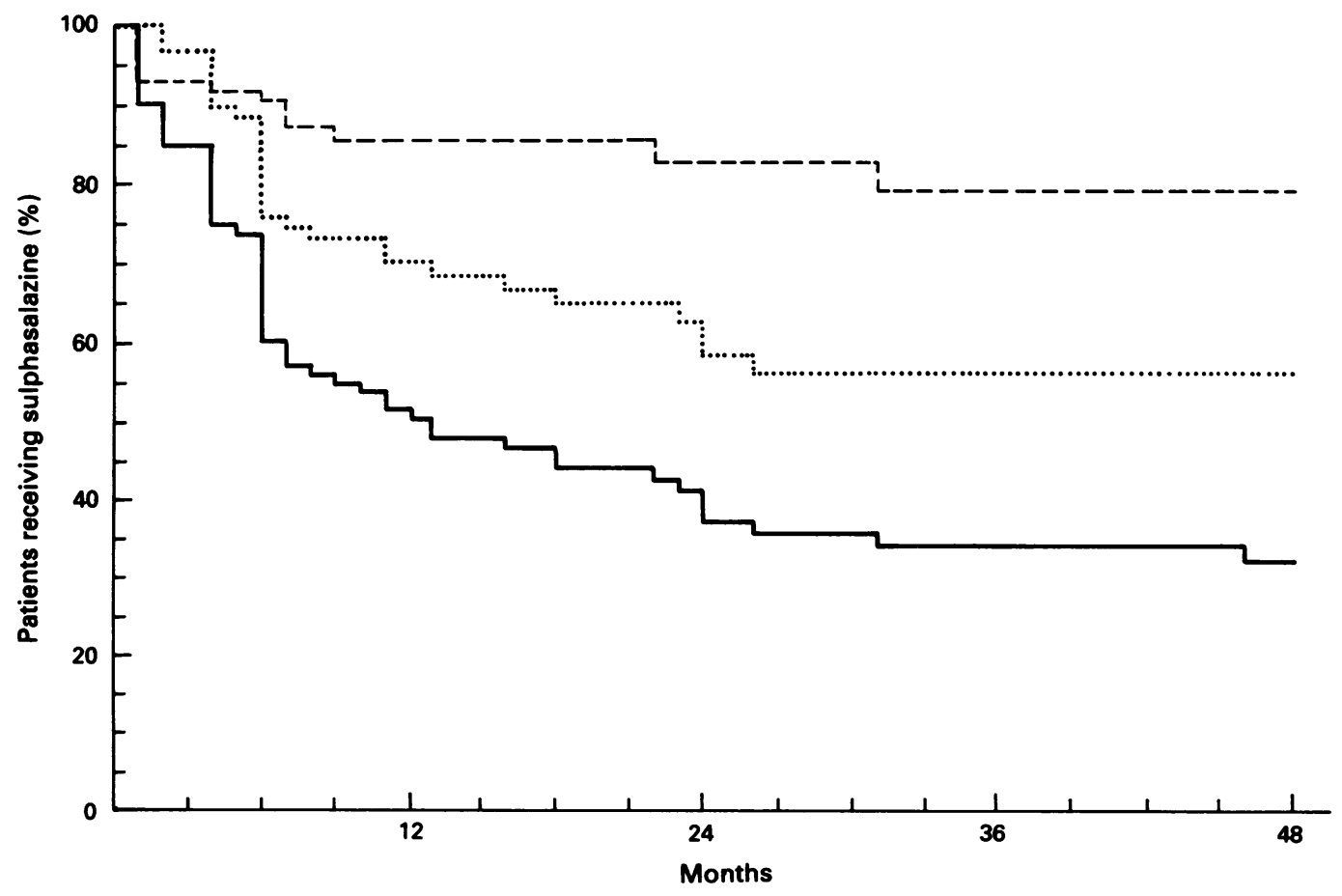


optimum doses of NSAIDs. This subgroup of patients represents only $27 \%$ of the group of patients with spondyloarthropathy treated in this department.

The reasons for treatment with sulphasalazine are based on our experience and knowledge of this drug. We consider sulphasalazine to be a slow acting drug as in a double blind placebo controlled study ${ }^{12}$ the group receiving sulphasalazine and the group receiving placebo diverged only after one to three months of treatment. As there are no data suggesting that sulphasalazine is a disease modifying drug in terms of the prevention of spinal ankylosis or the prevention of articular erosions, or both, we do not use this drug in patients who have mild disease or a disease which is well controlled by NSAIDs.

In this retrospective, open, uncontrolled study, we confirmed the favourable effects of sulphasalazine on the activity of the disease. After the first six months of treatment the clinical efficacy of the drug was considered sufficient by the doctor and the patient to be continued in 59 patients. This beneficial effect persisted during a long period of time as suggested by the statistically significant reduction in the efficacy variables between start and end of treatment (see table 2) and as also suggested by the low percentage of patients who had to discontinue the drug after the first six months of treatment (fig).

The side effects observed are those usually reported with sulphasalazine. As previously reported in rheumatoid arthritis, ${ }^{23} 24$ side effects occurred mostly in the first weeks after starting treatment, but some of the severe adverse reactions leading to the discontinuation of the drug occurred some months later (see fig and table 4). These late withdrawals because of toxicity suggest that close monitoring must be carried out as long as treatment is continued.

In this study we could not identify a subgroup of patients who might respond preferentially to treatment with sulphasalazine. These negative results suggest that sulphasalazine might improve the clinical status of patients with active spondyloarthropathy whatever the clinical presentation (spinal or peripheral articular disease, or both). The retrospective study design and the possible bias introduced by our definition of responder do not allow any definite conclusion, however, and suggest that further prospective controlled studies of sulphasalazine in the whole group of spondyloarthropathies are necessary to determine the factors predictive of beneficial treatment with sulphasalazine in patients with spondyloarthropathy.

1 Arnett F. Seronegative spondylarthropathies. Bull Rheum Dis 1987; 37: 1-12.

2 Moll J M H, Haslock I, MacRae I F, Wright V. Associations between ankylosing spondylitis, psoriatic arthritis, Reiter's
disease, the intestinal arthropathies and Behcet's syndrome. disease, the intestinal arthropathies and
Medicine (Baltimore) 1974; 53: 343-64.

3 Amor B, Dougados M, Mijiyawa M. Critère diagnostique des spondylarthropathies. Rev Rhum Mal Osteoartic 1990; 57: 85-9.

4 Dougados M, Van Der Linden S, Juhlin R, et al. The European Spondylarthropathy Study Group preliminary criteria for the classification of spondylarthropathy. Arthritis Rheum 1991; 34: 1218-27.

5 Dougados $M$. Diagnosis and monitoring of spondylarthropathy. Compr Ther 1990; 16: 52-6.

6 McConkey B, Amos R S, Durham S, Forster P J G, Huball S, Walsh L. Sulphasalazine in rheumatoid arthritis. $B M \mathcal{F}$ 1980; 280: 442-4.

7 Peppercorn M A. Sulphasalazine: pharmacology, clinical use, toxicity and related new drug development. Ann Intern Med 1984; 3: 377-86.

8 Mielants $\mathbf{R}$, Veys $\mathbf{E}$ M. Inflammation of the ileum in patients with B27 positive reactive arthritis. Lancet 1984; i: 288.

9 Dougados $M$, Alemanni $M$, Tulliez $M$, et al. Ileocolonoscopie systématiques au cours des spondylarthropathies séronégatives. Rev Rhum Mal Osteoartic 1987; 54: 279-83.

10 Ebringer R W, Cawdwell D R, Cowling P, Ebringer A Sequential studies in ankylosing spondylitis. Association of Klebsiella pneumoniae with active disease. Ann Rheum Dis 1979; 37: 145-51.

11 Amor B, Kahan A, Dougados M, Delrieu F. Sulphasalazine in ankylosing spondylitis. Ann Intern Med 1984; 101: 878.

12 Dougados M, Boumier P, Amor B. Sulphasalazine in ankylosing spondylitis: a double blind controlled study in 60 patients. BMF 1986; 293: 911-4.

13 Feltelius N, Hallgren $R$. Sulphasalazine in ankylosing spondylitis. Ann Rheum Dis 1986; 45: 396-9.

14 Nissila M, Lehtinen $K$, Leirisalo-Repo $M$, Luukkainen $R$ Mutru O, Yli-Kertula U. Sulphasalazine in the treatment of ankylosing spondylitis. Arthritis Rheum 1988; 31: 1111-6.

15 Davis M J, Dawes P T, Beswick E, Lewin I V, Stanworth D R. Sulphasalazine therapy in ankylosing spondylitis: its effect on disease activity, immunoglobulin $A$ and the complex immunoglobulin-A-(1-1-antitrypsin. Br $\mathcal{F}$ R heumatol 1989; 28: 410-3.

16 Corkill M M, Jabanputra P, Gibson T, MacFarlane D G. A controlled trial of sulphasalazine treatment of chronic ankylosing spondylitis: failure to demonstrate a clinical effect. $B r \mathcal{F}$ Rheumatol 1990; 29: 41-5.

17 Ferraz M B, Tugwell P, Goldsmith C H, Atra E. Metanalysis of sulphasalazine in ankylosing spondylitis. $\mathcal{J}$ Rheumatol 1990; 17: 1482-8.

18 Mielants H, Veys E M, Joos R. Sulphasalazine (Salazopyrine) in the treatment of enterogenic reactive synovitis and ankylosing spondylitis with peripheral arthritis. Clin Rherumatol 1986; 5: 80-3.

19 Farr M, Kitas G D, Waterhouse L, Jubb R, Felix-Davies D, Bacon P A. Treatment of psoriatic arthritis with sulphasalazine: a one year open study. Clin Rheumatol 1988; 7 372-7.

20 Farr M, Kitas G D, Waterhouse L, Jubb R, Felix-Davies D, Bacon P A. Sulphasalazine in psoriatic arthritis: a doubleblind placebo-controlled study. Br $\mathcal{F}$ Rheumatol 1990; 29: 46-9.

21 Gupta A K, Ellis C N, Siegel M T, et al. Sulphasalazine improves psoriasis. Arch Dermatol 1990; 126: 487-93.

22 Dougados M, Berenbaum F, Maetzel A, Amor B. The use of sulphasalazine for the prevention of attacks of acute anterior uveitis associated with spondylarthropathy [abstract]. Arthritis Rheum. In press.

23 Scott D L, Dacre J E. Adverse reactions to sulphasalazine: the British experience. $\mathcal{F}$ Rheumatol 1988; 15 (suppl 16): 17-21.

24 Lonauer G. Therapiestudie der chronischen Polyarthritis mit Sulphasalazin unter dem besonderen Aspeckt des Nebenwirkungsprofits. $Z$ Rheumatol 1990; 49: 44-9. 